Camillo Spöri, Pascal Briois, Hong Nhan Nong, Tobias Reier, Alain Billard, Stefanie Kühl, Detre Teschner, Peter Strasser

\title{
Experimental Activity Descriptors for Iridium-based Catalysts for the Electrochemical Oxygen Evolution Reaction (OER)
}

Journal article | Accepted manuscript (Postprint)

This version is available at https://doi.org/10.14279/depositonce-8720

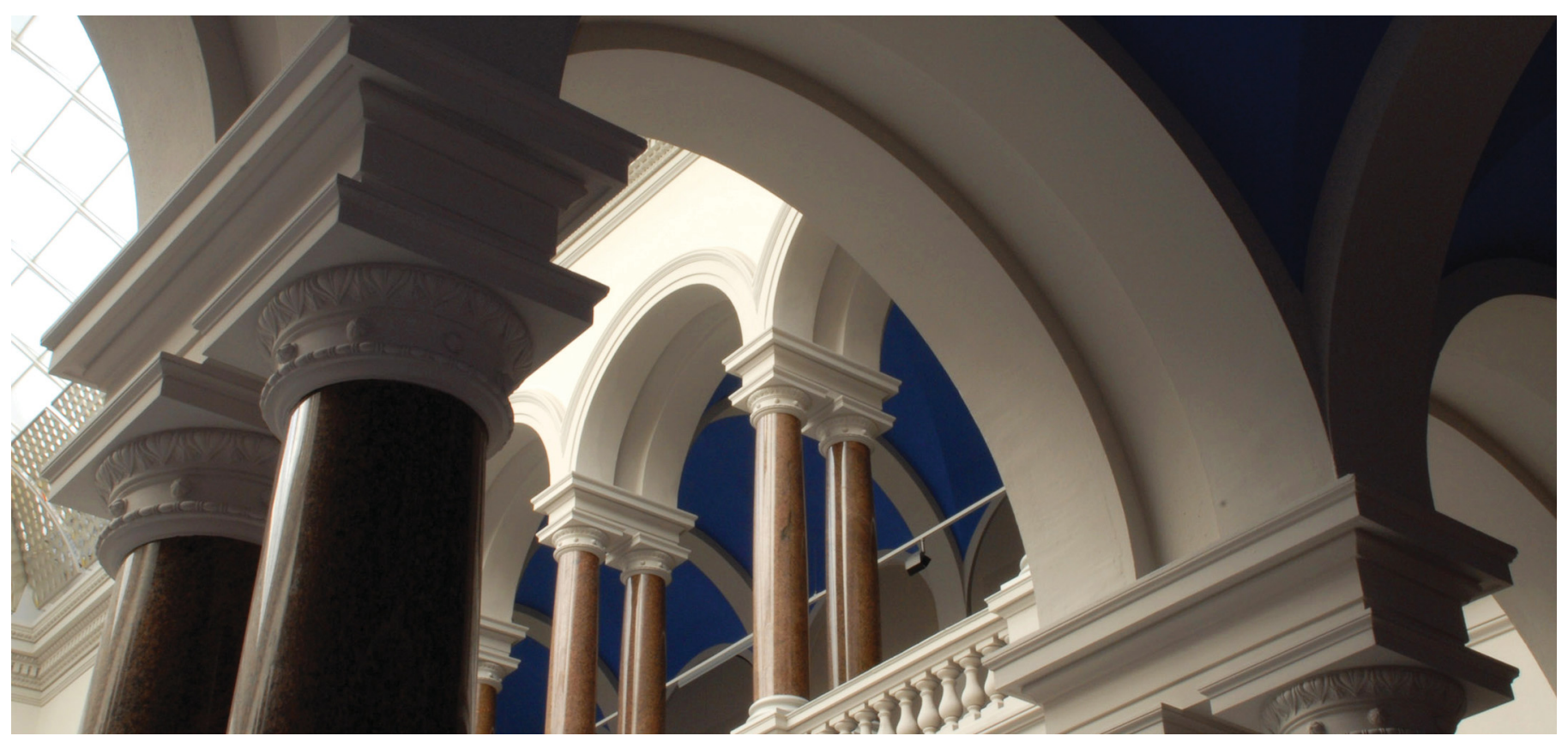

Spöri, C., Briois, P., Nong, H. N., Reier, T., Billard, A., Kühl, S., Teschner, D., Strasser, P. (2019).

Experimental Activity Descriptors for Iridium-Based Catalysts for the Electrochemical Oxygen Evolution Reaction (OER). ACS Catalysis, 6653-6663. https://doi.org/10.1021/acscatal.9b00648 


\title{
Experimental Activity Descriptors for Iridium-based Catalysts for the Electrochemical Oxygen Evolution Reaction (OER)
}

\author{
Camillo Spöri $i^{a}$, Pascal Briois ${ }^{b}$, Hong Nhan Nonga, ${ }^{a, c}$, Tobias Reier ${ }^{a}$, Alain Billard ${ }^{b}$, Stefanie Kühl ${ }^{a}$, Detre Teschner ${ }^{c, d}$, and Pe- \\ ter Strasser ${ }^{a, *}$ \\ a) The Electrochemical Catalysis, Energy and Materials Science Laboratory, Department of Chemistry, Technische Univer- \\ sität Berlin, Straße des 17. Juni 124, 10623 Berlin, Germany \\ b) FEMTO-ST (UMR CNRS 6174), Université de Bourgogne Franche-Comté, UTBM, 90010 Belfort, France \\ c) Max Planck Institute for Chemical Energy Conversion, Stiftstr. 34-36, 45470 Mülheim an der Ruhr, Germany \\ d) Fritz-Haber-Institut der Max-Planck Gesellschaft, Faradayweg 4-6, 14195 Berlin, Germany
}

\begin{abstract}
Recent progress in the activity improvement of anode catalysts for acidic electrochemical water splitting was largely achieved through empirical studies of iridium-based bimetallic oxides. However, practical, experimentally accessible, yet general predictors of catalytic OER activity are lacking. This study investigates iridium and iridium-nickel thin film model electrocatalysts for the OER and identifies a set of general ex situ properties that allow the reliable prediction of their OER activity. Well-defined Irbased catalysts of various chemical nature and composition were synthesized by magnetron sputtering. Correlation of physico-chemical and electrocatalytic properties revealed two experimental OER activity descriptors that are able to predict trends in the OER activity of unknown Ir-based catalyst systems. More specifically, our study demonstrates that the $\mathrm{Ir}^{\mathrm{III+}}$ - and $\mathrm{OH}$-surface concentration of the oxide catalyst constitute closely correlated, and generally applicable OER activity predictors. Based on these, an experimental volcano relationship of Ir-based OER electrocatalysts is presented and discussed.
\end{abstract}

Electrolysis, OER, Electrolyzers, Figures Of Merit, Water Splitting, Catalyst Design, Volcano Relationship, Oxide Formation and Growth

\section{Introduction}

With increasing capacities of renewable energies being installed worldwide, one of the most important requirements for industry and research alike is the development of suitable energy storage solutions. Among the most promising suggestions is (photo-)electrochemical water splitting that can be effectively done in ion exchange membrane electrolyzers. ${ }^{1}$ Here, proton exchange membrane (PEM) electrolysis is predicted to be the state-of-the-art technology in short and medium term development. ${ }^{2}$ Due to the acidic environment of proton exchange membranes, iridium has been widely accepted as standard anode catalyst in PEM water electrolysis with the best compromise of activity and stability. ${ }^{3}$ However, despite the huge effort the reaction mechanism as well as the active species or structure have not been fully elucidated and are subject to intense discussion in the field. ${ }^{4-7}$ Besides activity descriptors like the adsorption energy difference between the $* \mathrm{OH}$ and $* \mathrm{OOH}$ intermediates, as they are often used in density functional theory (DFT) calculations, other catalyst properties can be used as descriptors as well. ${ }^{8}$ While the investigation of active species of Ir-based catalysts is crucial, it is restricted to complex in operando measurements. Hence, several approaches to identify activity descriptors from the as prepared state have been made. ${ }^{9-11}$ The superior activity of electrochemically oxidized iridium over thermally oxidized iridium is usually attributed to a more amorphous and hydrated structure of the former. ${ }^{12}$ Recent efforts correlate a three-dimensional reaction regime in the electrochemically oxidized case to the increased activity. ${ }^{13}$ Reier et al. show that iridium oxide thin films calcined at high and low temperatures retain different ratios of $\mathrm{OH}$-surface species and two chemically distinct oxide types that correlate with the observed activity trend. ${ }^{14}$ Özer et al., indicate that the exposed facets of an iridium catalyst may have an influence on the initial activity. ${ }^{15}$ Given that the current understanding of the OER mechanism suggests strong surface amorphization and participation of the lattice oxygen, ${ }^{3,5,11}$ one can easily assume the loss of a distinct long range order of surface facets during the reaction. However, Willinger et al. propose the importance of short range order structural motifs for the iridium OER activity. ${ }^{16}$ Their amorphous iridium(hydr)oxide catalyst is suggested to consist of tunnel-like hollandite clusters that are stabilized by $\mathrm{K}^{+}$ions in the tunnels. The flexibility of these short range motifs is supposed to accommodate the surface amorphization during OER. Flexible surface motifs are reported to promote OER activity by faster formation of active species by Saveleva et al. as well. ${ }^{17}$ In attempts to reduce the expensive iridium content several iridium-based mixed metal oxides have been investigated with $\mathrm{IrNi}$ and IrCo mixed metal oxides being the most prominent ones. ${ }^{18-19}$ On IrNi oxide thin film catalysts a dependency of the $\mathrm{OH}$ surface ratio to the initial $\mathrm{Ni}$ content has been observed. ${ }^{20}$ The initial Ni leaching is suggested to lead to a surface restructuring that removes oxide surface terminations and reduces the oxidation state of remaining Ir species. A similar restructuring can be expected for the IrNi core-shell particles reported by Nong et al. albeit the shell consists of Ir oxide only after the $\mathrm{Ni}$ leaching. ${ }^{19,21}$ In contrast to thin films the particles retain a metallic IrNi core and their active site was recently suggested to be 
an electrophilic oxygen species $\left(\mathrm{O}^{(\mathrm{II}-\delta)}\right)$ with reduced $\mathrm{Ir}-\mathrm{O}$ bond distance. ${ }^{22}$ Alia et al. recently presented an extensive study on Ir based mixed metal oxide nanowires (nw) with either $\mathrm{Ni}$ or $\mathrm{Co}$ content. ${ }^{18}$ For both types an increased $\mathrm{OH}$-surface ratio with increasing initial $\mathrm{Ni} / \mathrm{Co}$ content was observed. In addition, Kuo et al. uncovered an experimental relationship between the oxygen adsorption energy and OER kinetics of $\mathrm{IrO}_{2}(110) .{ }^{23}$ Besides fundamental mechanistic investigations, the challenges of stabilizing Ir-based catalysts remain as was recently highlighted by several authors. ${ }^{24-27}$

Starting from our current understanding of composition, structure and morphology of a family of highly active IrNi bimetallic OER electrocatalysts, this study unravels general experimental activity predictors for different types of Iridium-based OER electrocatalysts. The predictive power of these descriptors advances our understanding of the oxygen evolution electrochemistry and facilitates the design of new, efficient water oxidation electrocatalysts.

\section{Experimental Procedures}

\section{Sample preparation}

Thin film catalysts were prepared on Ti disc substrates $(10 \mathrm{~mm}$ diameter, 4mm thickness, Ti grade 1, Gemmel Metalle, Germany) that were polished to a mirror like finish in a three step process using a half automatic polishing machine (AutoMet 250, Buehler). To remove surface impurities, polished Ti cylinders were treated in hot nitric acid (23\%, prepared by dilution of $69 \% \mathrm{HNO}_{3}$, AnalaR Normapur) in a final step. ${ }^{28}$

$\mathrm{Ir}(\mathrm{Ni})(\mathrm{O})$ coatings were deposited by reactive DC magnetron sputtering using Ir and Ni metallic targets on a rotating substrate holder in the presence of argon-oxygen reactive gas mixtures at UTBM. Besides polished Ti cylinders, glass slides, alumina and $\mathrm{Si}$ wafers were used as substrates. The received samples were investigated as prepared or subjected to an additional heat treatment at TU Berlin. Heat treatment was conducted in a rapid temperature tube furnace with a moving heating stage (MTI Corp., USA) at $450{ }^{\circ} \mathrm{C}$ for $20 \mathrm{~min}$ in Ar or synthetic air (Air Liquide) for the metallic and oxide samples, respectively. Detailed information on sample preparation and heat treatment can be found in the SI.

\section{Physicochemical characterization}

All samples were subjected to grazing-incidence X-ray diffraction (GI-XRD), scanning electron microscopy (SEM) and energy-dispersive X-ray spectroscopy (EDX) in their as prepared, heat-treated and after OER state.

GI-XRD measurements were run on a D8 Advance lab XRD (BrukerAXS Microanalysis GmbH, Germany) with Cu K- $\alpha$ XRay tube, Goebel mirror, $0.28^{\circ}$ soller slit and a scintillation counter point detector. Measurements were conducted at $1^{\circ}$ incidence angle, from $20-80^{\circ} 2 \theta$ with a $0.06^{\circ}$ step size. Rietveld refinement was applied with the TOPAS software package (Bruker, Germany).

SEM-EDX was conducted on a JEOL $7401 \mathrm{~F}$ field emission scanning electron microscope operated at $10 \mathrm{kV}$. Images were acquired in secondary electron mode. EDX spectra were acquired of at least three separate areas of each sample in the as prepared, heat treated (where applicable) and after OER state with a Quantax 400 detector (BrukerAXS Microanalysis $\mathrm{GmbH}$, Germany) attached to the JEOL 7401F. EDX spectra were evaluated with the Esprit software package (Bruker, Germany).

A scanning transmission electron microscopy (S/TEM) crosssection of $\mathrm{IrNi} / \mathrm{NiO} \mathrm{HT}-\mathrm{OER}$ was acquired by preparing a TEM lamella by Focussed Ion Beam (FIB). The TEM and STEM measurements were performed at a FEI Tecnai $\mathrm{G}^{2} 20$ S-TWIN transmission electron microscope with $\mathrm{L} \mathrm{LaB}_{6}$ cathode operated at an accelerating voltage of $200 \mathrm{kV}$. Detailed descriptions of (S)TEM-EDX, SAED and the FIB operation can be found in the supplemental information. The SAED evaluation was performed with the PASAD ${ }^{29-30}$ plugin in Gatan Digital Micrograph $^{\mathrm{TM}}$. The obtained reciprocal distances were transferred to $\mathrm{Cu} \mathrm{K}-\alpha$ scale to compare the calculated diffraction patterns to the PDF database. All electron micrographs (SEM, TEM and STEM) were evaluated with ImageJ (Version 1.48, W.S. Rasband, NIH, USA).

X-ray photoelectron spectroscopy (XPS) of the as prepared, heat treated and after OER states of the samples was carried out at room temperature using non-monochromatized $\mathrm{Al} \mathrm{K} \alpha$ (1486.6 eV) excitation and a hemispherical analyzer (Phoibos 150, SPECS). The binding energy (BE) scale was calibrated by the standard $\mathrm{Au} 4 \mathrm{f} 7 / 2$ and $\mathrm{Cu} 2 \mathrm{p} 3 / 2$ procedure. To calculate the elemental composition, theoretical cross sections from Yeh and Lindau $^{31}$ were used. The XP spectra were analyzed using the CasaXPS software.

\section{Electrochemical characterization and performance}

Electrochemical measurements were performed at room temperature in an RDE setup with a three-compartment electrochemical cell equipped with a Luggin-capillary, PINE rotator (MSRE, Pine Research Instrumentation, USA) and an SP-200 or SP-150 potentiostat (BioLogic, France). The electrolyte for all experiments, $0.1 \mathrm{M} \mathrm{HClO}_{4}$, was diluted from $70 \% \mathrm{HClO}_{4}$ (Sigma-Aldrich, $99.999 \%$ purity) with 18 MOhm cm Milli-Q water (Synergy UV, Merck Millipore). A Pt mesh attached to a Pt wire was used as counter electrode and a saturated mercury/mercury-sulfate electrode was used as reference electrode. The latter was calibrated against a reversible hydrogen electrode (RHE) in the same electrolyte regularly. All potentials in this publication are converted and referred to the RHE scale. A custom made PEEK-tip was used for the working electrode to incorporate the $10 \mathrm{~mm}$ diameter catalyst substrates. The exact electrochemical protocol was published elsewhere ${ }^{20}$ and can be found in the SI. For each catalyst at least three individual measurements were conducted on separately synthesized samples.

\section{Results and Discussion}

$\mathrm{IrNi} / \mathrm{IrNiOx}$ catalysts were chosen alongside $\mathrm{Ir} / \mathrm{IrOx}$ as model catalyst system to catalyze the acidic oxygen evolution reaction (OER) or equivalently, water oxidation reaction. The selected Ir-to-Ni ratio of near 80 atomic $\%$ initial $\mathrm{Ni}$ content matched the Ir-to-Ni ratio for which earlier studies reported an OER activity maximum. ${ }^{20}$ In order to establish experimental property-activity relationships and eventually derive activity descriptors, sample sets of a metallic IrNi alloy and an IrNi oxide were prepared as thin films on Ti disc substrates by magnetron sputtering (see experimental). A variety of well-defined metallic and oxidic Ir and IrNi thin film catalysts was prepared, mimicking the most promising OER catalysts recently published. In particular, these samples resemble the initial state of highly active IrNi nanoparticles (henceforth referred to as $\operatorname{IrNi} N P S^{19}$ ) and $\mathrm{IrNiOx}$ thin 
film (henceforth referred to as $\mathrm{IrNiOx} T F^{20}$ ) catalysts. One sample set was investigated in its "as prepared" state mimicking the IrNi NPs, whereas a second set was heat treated prior to further investigation in order to mimic the $\mathrm{IrNiOx} T F$ preparation. Sets of reference Ir and IrOx catalyst were prepared accordingly. Samples are denoted $\operatorname{IrNi}(H T), \operatorname{IrNiOx}(H T), \operatorname{Ir}(H T)$ and IrOx (HT) throughout the manuscript, whereby the suffix HT denotes heat-treated samples. Further suffixes " $-a p$ " and "-OER" indicate whether the samples were investigated in their as prepared or OER tested states, respectively. Additionally, an IrNi sample heat-treated at reduced partial pressure of oxygen was investigated ( $\mathrm{IrNi} / \mathrm{NiO} \mathrm{HT})$.

\section{Electrochemical analysis and performance}

Initial catalytic OER activities - measured at $1.53 \mathrm{~V}_{\text {RHE }}$ as geometric, specific and mass-based current density in the beginning of the electrochemical protocol - are presented in Fig. S1 and Table S1. Interestingly, the initial specific activities of $\mathrm{IrNi}$ and IrNi HT are almost identical and similar to the steady state activity of IrNi HT (compare Fig. S1 and Fig. 1a). The latter could indicate that stabilization of the initial state of $\operatorname{IrNi}$ could lead to improved performance.

In the steady state, presented in Fig. 1a, the monometallic iridium catalysts perform comparably. Except for $I r$, which shows improved geometric and specific performance with its specific activity being on a similar level to the bimetallic catalysts. This surprisingly high activity has been observed by other groups as well but could not be fully explained yet. ${ }^{32}$ Besides $I r$, the mixed metal (oxide) catalysts clearly outperform all monometallic materials. The samples $\mathrm{IrNi}$, IrNi HT and $\mathrm{IrNi} / \mathrm{NiO} \mathrm{HT}$, designed to mimic the IrNi core-shell NPs, perform distinctly different from each other. Similar to $\operatorname{IrNi} N P S^{19}$, heat treatment led to a strong activity decrease as soon as small amounts of oxygen are present $\left(\mathrm{IrNi} / \mathrm{NiO} \mathrm{HT}\right.$ shows $1 / 10^{\text {th }}$ of geometric and mass based current density of $\operatorname{IrNi}$, specific activity is $\sim 1 / 2$ ). In contrast to IrNi NPS, heat treatment of IrNi under oxygen exclusion resulted in increased activities and presented the most active catalyst among the investigated set ( IrNi HT).
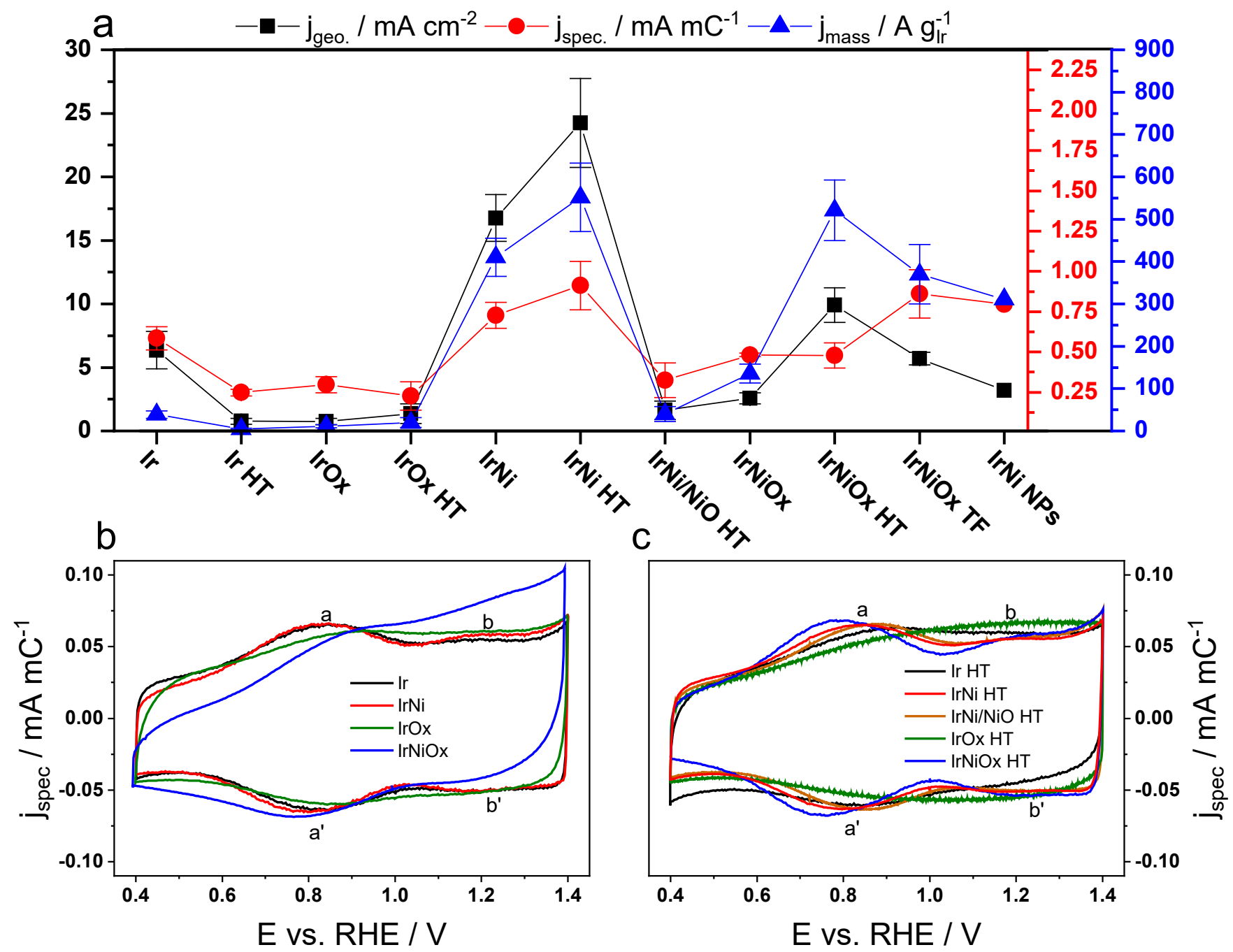

Fig. 1: a) electrocatalytic activities of the investigated sample set and template materials given as geometric, specific and mass based current density at $1.53 \mathrm{~V}_{\mathrm{RHE}}(300 \mathrm{mV}$ overpotential, iR corrected). Catalysts are denoted by their initial composition as described in the introduction. Activity data for $\mathrm{IrNiOx} T \mathrm{FF}^{20}$ and $\mathrm{IrNiNPS^{19 }}$ are taken from the respective references. b) Cyclovoltammetry of -OER and c) HT-OER samples with redox features $\mathrm{a} / \mathrm{a}$ ' and b/b'. Specific current density normalized to total anodic charge in the displayed potential range; scan rate $50 \mathrm{mV} \mathrm{s}^{-1}$. 
For the monometallic samples in this study, heat treatment led to declining steady-state OER activities (Fig. 1a). However, IrNi HT and IrNiOx HT exhibited higher OER activities than their non-heat-treated counterparts did. Though, on $\mathrm{IrNiOx} H \mathrm{HT}$ this is only true for geometric and mass activities as the specific activities of $\mathrm{IrNiOx}$ and $\mathrm{IrNiOx} H \mathrm{HT}$ coincided. This could partially be explained by the electrochemical redox behavior of $I r-$ $\mathrm{NiOx}$ vs. IrNiOx HT (see Fig. $1 \mathrm{~b}$ and c, asymmetric behavior in redox peaks) which indicates low conductivity in or slow kinetics on IrNiOx. However, contact problems between Ti and catalyst were not observed in potentiostatic electrochemical impedance spectroscopy (PEIS) measurements at any time. Further sintering during heat treatment could mitigate the disadvantage of low conductivity within the layer and thus lead to the observed activity increase. A similar effect, however, can be expected for catalyst loss that affects geometric and mass-based

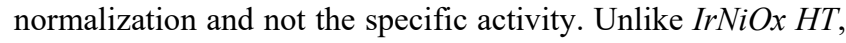
IrNi HT shows an increase in all three OER activities (geometric, mass-based and specific) over $\mathrm{IrNi}$ indicating an actual change in the intrinsic activity. Tafel slopes (see Table 1) reflected the observed activity trend. All Tafel slopes were in the

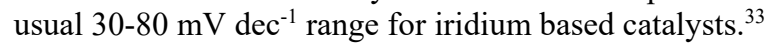

Fig. $1 \mathrm{~b}$ and $\mathrm{c}$ illustrate the reversible surface redox features of all samples in the corresponding charge normalized cyclovoltammograms (CVs; the charge normalization method is described in the supporting information). These CVs showed at least one distinct redox feature a/a' $(\sim 0.75-0.90 \mathrm{~V}$ RHE $)$ usually attributed to the $\mathrm{Ir}^{\mathrm{II}+} / \mathrm{Ir}^{\mathrm{IV}+}$ transition. ${ }^{34}$ A second redox feature $\mathrm{b} / \mathrm{b}$ ' at more positive potentials $\left(\sim 1.2 \mathrm{~V}_{\mathrm{RHE}}\right)$ appeared on the mixed metal (oxide) catalysts only. This redox feature is sometimes assigned to further deprotonation of $\mathrm{OH}$ surface sites in the literature. ${ }^{35}$ The position of redox feature a/a' can be interpreted as a measure of the oxidizability of the respective Irbased oxide. The total anodic charge $\mathrm{Q}_{\text {anodic }}$ in this potential range was taken as a relative figure for the electrochemically active $\operatorname{Ir}(\mathrm{Ox})$ surface area ${ }^{28,36}$ and was used to calculate the specific current density here, allowing a more precise comparison of the CVs (see experimental section). Remarkably, all highly active catalysts were characterized by large Qanodic, a more negative peak position for redox transition a/a' and low Tafel slopes. Peak positions and the corresponding anodic charge are presented in Table 1.

Table 1: Redox peak positions, total anodic charge measured between 0.4-1.4 $\mathrm{V}_{\mathrm{RHE}}$ and Tafel slopes of the sample set.

\begin{tabular}{|l|l|l|l|l|l|l|l|l|}
\hline \multirow{2}{*}{ sample } & \multicolumn{2}{l}{ (a) peak position / V } & \multicolumn{2}{l|}{ (b) peak position / VRHE } & \multicolumn{2}{l|}{ Qanodic / mC } & \multicolumn{2}{l|}{ Tafel slope / mV dec-1 } \\
\cline { 2 - 10 } & -OER & HT-OER & -OER & HT-OER & -OER & HT-OER & -OER & HT-OER \\
\hline Ir & 0.83 & 0.87 & - & - & $8.4 \pm 1.0$ & $3.4 \pm 1.5$ & 45 & 48 \\
\hline IrOx & 0.84 & 0.92 & - & - & $1.9 \pm 0.4$ & $4.4 \pm 1.2$ & 71 & 46 \\
\hline IrNi & 0.81 & 0.80 & 1.18 & 1.19 & $18.2 \pm 0.5$ & $20.9 \pm 0.4$ & 35 & 37 \\
\hline IrNi/NiO & - & 0.86 & - & 1.19 & - & $4.0 \pm 1.7$ & - & 64 \\
\hline IrNiOx & 0.87 & 0.79 & 1.24 & 1.18 & $4.2 \pm 0.6$ & $16.9 \pm 0.8$ & 50 & 33 \\
\hline
\end{tabular}

Physicochemical Characterization

GI-XRD patterns are given in Fig. S2 for all samples in their -ap (Fig S2a) and -OER states (Fig. S2b). Ir-ap and IrNi-ap could be attributed to the corresponding metallic Ir phase with the reflex positions being shifted corresponding to the $\mathrm{Ni}$ insertion for IrNi-ap while IrOx-ap revealed a single, broad reflection around $34^{\circ} 2 \theta$ only. Heat treatment led to an increase in crystallinity for Ir HT-ap, and IrNi HT-ap. IrOx HT-ap was well in line with the $\mathrm{IrO}_{2}$ patterns of similarly calcined thin films presented elsewhere. ${ }^{14,20} \mathrm{On} \mathrm{IrNi} / \mathrm{NiO} \mathrm{HT}$-ap the heat treatment in presence of oxygen residues produced an additional phase that could be identified as $\mathrm{NiO}$ (bunsenite) by comparison to reference patterns from the PDF database and by Rietveld refinement (see Fig. S3). Rietveld refinement of IrOx-ap and $-H T$ presented in Fig. S4 exemplarily shows a substoichiometric TiOx phase (hongquiite) that was visible on all non-heat-treated samples. IrNiOx-ap and IrNiOx HT-ap were completely X-ray amorphous, comparable to the template $\mathrm{IrNiOx} T F$ catalyst of similar composition. ${ }^{20}$ After OER (Fig. S2b), the nonheat-treated samples showed decreasing (metallic samples) to no (oxidic samples) XRD reflexes. No additional phases emerged on any of the samples. Surprisingly, the observed $\mathrm{NiO}$ phase remained on $\mathrm{IrNi} / \mathrm{NiO} \mathrm{HT}-\mathrm{OER}$.

Table 2 gives the average crystallite size of the main phase in each catalyst in the -ap, HT-ap and (HT)-OER states. Heat treat- ment leads to increased crystallinity and crystallite size respectively. Crystallite sizes for $\mathrm{IrNiOx}(H T)$ and $\mathrm{IrOx}$-ap could not be obtained due to the X-ray amorphous structure of the catalyst layers.

Table 2: Crystallite sizes obtained by Rietveld refinement of GI-XRD patterns. For $\mathrm{IrNi} / \mathrm{NiO}$ HT crystallite sizes are given for the $\mathrm{NiO}$ as well as the IrNi phase indicated by bold letters for the respective phase in the sample column.

\begin{tabular}{|l|l|l|l|l|}
\hline \multicolumn{6}{|l|}{ crystallite size / nm } \\
\hline sample & -ap & -OER & HT-ap & HT-OER \\
\hline $\mathrm{Ir}$ & $7.2 \pm 1.2$ & $5.5 \pm 0.4$ & $17.2 \pm 1.3$ & $12.8 \pm 0.7$ \\
\hline $\mathrm{IrNi}$ & $3.3 \pm 1.3$ & $3.2 \pm 0.7$ & $6.6 \pm 0.4$ & $3.2 \pm 0.3$ \\
\hline $\mathrm{IrNi} / \mathrm{NiO}$ & & & & \\
$-\mathbf{I r N i}$ & - & - & $4.1 \pm 0.6$ & $5.6 \pm 2.3$ \\
$-\mathbf{N i O}$ & - & - & $10.4 \pm 1.8$ & $11.1 \pm 2.2$ \\
\hline $\mathrm{IrOx}$ & - & - & $7.4 \pm 1.3$ & $7.3 \pm 2.3$ \\
\hline $\mathrm{IrNiOx}$ & - & - & - & - \\
\hline
\end{tabular}

SEM images shown in Fig. 2 revealed a very similar, flat and smooth surface structure for Ir-ap (Fig. 2a) and IrNi-ap (Fig. 2b) as well as $I r O x$-ap and IrNiOx-ap (Fig. 2c, d respectively). The metallic samples showed microcracks in the low nanometer range (up to $1 \mu \mathrm{m}$ length, 3-6 $\mathrm{nm}$ width), whereas the oxidic 
samples seemed almost crack-free (10-40 nm length; $\leq 2 \mathrm{~nm}$ width). After heat treatment some surface cracks were induced in the oxidic samples (Fig. 2k, l) and IrNi HT-ap (Fig. 2j). No further change was observed, except for $\mathrm{IrNi} / \mathrm{NiO} \mathrm{HT}$-ap which changed from a flat, smooth surface to wrinkled platelets (see Fig. S5a) that resemble $\mathrm{NiO}$ catalysts presented in the literature but on a much smaller length scale here. ${ }^{37}$ The emergence of $\mathrm{NiO}$ is in line with the corresponding XRD pattern, indicating the formation of a rather thick $\mathrm{NiO}$ layer. In fact, it seemed that this structure had formed on top of the initial morphology.

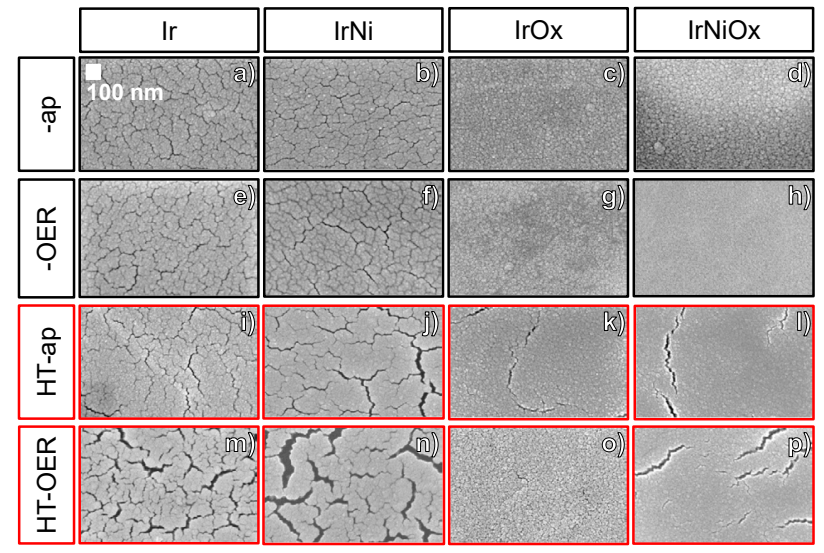

Fig. 2: Top view SEM micrographs of the investigated samples depicting the catalyst layer surface in the as prepared (a-d), electrochemically tested (e-h), heat treated (i-l) and heat treated and electrochemically tested (m-p) states of the compositions $\operatorname{Ir}(\mathrm{a}, \mathrm{e}, \mathrm{i}, \mathrm{m})$, $\operatorname{IrNi}(\mathrm{b}, \mathrm{f}, \mathrm{j}, \mathrm{n}), \operatorname{IrOx}(\mathrm{c}, \mathrm{g}, \mathrm{k}, \mathrm{o})$ and $\operatorname{IrNiOx}(\mathrm{d}, \mathrm{h}, \mathrm{l}, \mathrm{p})$, respectively. The scale bar for all subfigures is given in a).

After electrocatalytic operation, IrOx-OER and IrNiOx-OER lost most of the catalyst layer due to dissolution or delamination (see Fig. S6 for photos of the electrodes after OER). On Ir-OER and $\mathrm{IrNi}$-OER catalyst loss occurred to a much lower extent while minimal to no damage was observed on the HT-OER samples visually (see Fig. S6). Where there was catalyst layer left, SEM micrographs revealed no change in the structure of the $-O E R$ samples (Fig. 2e-h). On the HT-OER samples, increased surface cracking (Fig. 2m-p) was observed. On $\mathrm{IrNi} / \mathrm{NiO}$ HT-OER, the platelets formed a denser NiO surface layer that was disrupted by small holes (Fig. S5b).

Interestingly, despite the less cracked structure of the oxides versus the metals, catalyst layer degradation (e.g. corrosion, delamination etc.) turned out to be a major problem on the former only. Possibly owing to their smaller crystallite size and, therefore, decreased interconnection the catalyst layers of the non-heat-treated oxides were heavily damaged during OER. The bonding between a sputtered metal vs. an oxide and the metallic substrate can also play a role in catalyst adhesion. A recent study found that the electrochemical oxidation of sputtered Ir films took place at the grain boundaries, possibly leading to an increase in film stability by improved grain interconnection. ${ }^{13}$ This would explain the reduced corrosion on the metallic versus the non-heat-treated oxide samples. Minimal catalyst loss on all HT-OER samples suggested a stronger catalyst adhesion and improved integrity of the layers to be a major influence of heat treatment.

To elucidate the structure of the emerging $\mathrm{NiO}$ layer and its stability, (scanning) transmission electron microscopy (S/TEM), selected area electron diffraction (SAED), as well as STEM-
EDX line scans were performed on a cross-section sample of $\mathrm{IrNi} / \mathrm{NiO} \mathrm{HT}-\mathrm{OER}$ (see Fig. S7-S11) revealing a roughly $25 \mathrm{~nm}$ thick $\mathrm{NiO}$ layer on top of an extended IrNi layer ( $\sim 134 \mathrm{~nm}$ vs. $\sim 87 \mathrm{~nm}$ on IrNi-ap, see Fig. S12 and S13). Most likely, the catalyst layer expanded during the Ni oxidation due to the distinct diffusivities of $\mathrm{Ir}$ and $\mathrm{Ni}$, especially in $\mathrm{NiO}$ as well as due to the $\mathrm{NiO}$ formation inside the formed pores and holes. The IrNi bulk layer was characterized by pores and holes filled with $\mathrm{NiO}$. STEM-EDX line scans (see Fig. S8) revealed a clear distinction between the IrNi bulk and $\mathrm{NiO}$ surface layers, whereas a mixed interlayer existed between support and catalyst layer. Inside the $\mathrm{NiO}$ layer, indications for Ir-containing crystallites were found by analysis of lattice fringes. A detailed description of the crosssection analysis can be found in the SI.

SEM cross-section (see Fig. S12 and S13) of all - ap and HT-ap samples revealed a layer thickness of about $80 \mathrm{~nm}$ for all -ap catalysts. Here, heat treatment led to a slight layer shrinkage possibly due to sintering.

SEM-EDX results shown in Fig. 3a and b (bulk, open triangles and dashed lines) confirmed the composition of all -ap mixed metal (oxide) samples to be Ir:Ni 17:83, well in line with XRD results. No change was observed for the HT-ap samples. After electrocatalysis the samples retain various reduced $\mathrm{Ni}$ contents. Only, $\mathrm{IrNi} / \mathrm{NiO}$ HT-OER showed no Ni loss (Ir:Ni 18:82). XPS analysis confirmed the Ir:Ni surface ratio (full triangles and lines in Fig. 3a and b) of the - ap catalysts to be in line with EDX results, except for $\mathrm{IrNi} / \mathrm{NiO} \mathrm{HT}$-ap where the rather thick $\mathrm{NiO}$ surface layer formation prevented any Ir to be detectable. Ir:Ni surface ratios after electrocatalysis suggested the formation of a nickel-depleted near-surface IrOx overlayer on $\mathrm{IrNi}-\mathrm{OER}$ and IrNi HT-OER with about $6.4 \%$ and $0 \% \mathrm{Ni}$, respectively. In line with EDX observations, $\mathrm{IrNi} / \mathrm{NiO}$ HT-OER retained most of its $\mathrm{Ni}$ with a small Ir signal emerging in the near-surface region. The surface concentration of $\mathrm{Ni}$ in IrNiOx HT-OER $(20.6 \%)$ was slightly lower than in the bulk (25\%, Fig. 3B), whereas IrNiOx-OER (similar bulk Ni concentrations) had no Ni left in the surface which fits very well to $\mathrm{IrNiOx} T F$ catalysts with the same starting composition. ${ }^{20}$
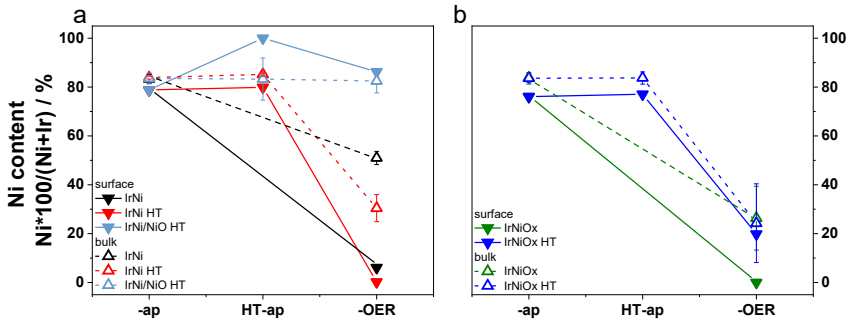

Fig. 3: Relative Ni content of a) $\operatorname{IrNi}(/ \mathrm{NiO})(\mathrm{HT})$ samples and b) IrNiOx (HT) samples by SEM-EDX (bulk, open symbols and dashed lines) and XPS (surface, solid symbols and lines) analysis.

The oxygen content of these samples (both EDX and XPS) is depicted in Fig. S14. On the metallic catalysts the (bulk) oxygen content increased to a lower extent in the -HT and -OER states than on the oxides, indicating the formation of a thin oxide layer with unchanged metallic parts of the bulk catalyst underneath.

XPS probed the surface layers of the $-a p$ and $-O E R$ catalysts. In the measurements presented here, the inelastic mean free paths (IMFP) are 1.9, 1.4 and $1.0 \mathrm{~nm}$ for Ir4f, O1s and Ni2p respectively. The fitted XPS spectra can be found in the supporting information (See Fig. S15 through S20). The Ir $4 \mathrm{f}_{7 / 2}$ 
peak consisted of three contributions $\left(\mathrm{Ir}^{0}, \mathrm{Ir}^{\mathrm{IV}+}\right.$ and $\mathrm{Ir}^{\mathrm{III}+}, \sim 60.8$, $\sim 61.7$ and $\sim 62.3 \mathrm{eV}$ respectively, see Fig. $4 \mathrm{a}, \mathrm{b}$ and SI). Despite ongoing debate about the true origin $\left(\mathrm{Ir}^{\mathrm{III}+}\right.$ or $\mathrm{Ir}^{\mathrm{V}+}$ ) of the last feature at $\sim 62.3 \mathrm{eV}$ under in operando conditions, it is denoted as $\mathrm{Ir}^{\mathrm{III}+}$ in this work as it seems highly unlikely that $\mathrm{Ir}^{\mathrm{V}+}$ could exist ex situ..$^{6-7,38}$ Nevertheless, it should be noted that we cannot completely rule out an $\mathrm{Ir}^{\mathrm{V}+}$ contribution at similar binding energies and we would not necessarily draw the same conclusions on in operando XPS data. See Fig. S15 for Ir4f and O1s spectra of $\mathrm{IrNi} / \mathrm{NiO} H \mathrm{HT}-\mathrm{OER}$, Fig. S16 for Ir4f species of all -OER samples and Fig. S17 for the fitted Ir4f spectra.

IrOx HT-ap and -OER consist of $\mathrm{Ir}^{\mathrm{IV}+}$ only, proving the formation of a pure rutile oxide phase (Fig. S16). Interestingly, IrOx-ap showed an $\operatorname{Ir}^{0}$ contribution, which was decreasing ( $\sim 23 \%$ to $\sim 6.5 \%$ ) but still present after electrochemical testing. Since the samples were prepared by sputtering of metallic targets in oxygen atmosphere, it seems possible that the -ap oxide contained metallic states which were not fully oxidized electrochemically. An unexpected reemergence of $\operatorname{Ir}^{0}$ was observed on $\mathrm{IrNi} / \mathrm{NiO} \mathrm{HT}-\mathrm{OER}$, indicating metallic Ir contributions in the vicinity of the electrochemically active surface (cf. Fig. 4a and b). Similarly, small $\mathrm{Ir}^{0}$ contributions remained on $\operatorname{IrNi}-\mathrm{OER}$ and IrNi HT-OER. The latter showed a surprisingly high $\mathrm{Ir}^{\mathrm{IV}+}$ contribution $(\sim 68 \%)$ fitting those of IrNiOx-OER and IrNiOx HT-OER.

The Ni2p peak was not fitted but compared to reference spectra of $\mathrm{NiO}$ and $\mathrm{Ni}(\mathrm{OH})_{2}$ as well as to the position of metallic $\mathrm{Ni}$ (852.6 eV) in Fig. S18. IrNi-ap and IrNi HT-ap showed a strong metallic Ni component, corresponding well to the metallic character in the Ir4f spectra further proving the IrNi alloy formation and stability during heat treatment. The Ni2p peak of IrNi/NiO HT (-ap and-OER) closely resembled NiO, whereas the oxidic samples and all other bimetallic -OER samples were more similar to $\mathrm{Ni}^{\mathrm{I}+}$ hydroxide.

The distribution of oxygen species detected in the O1s spectra (see Fig. 4c, d) supports the findings from Ir4f and Ni2p spectra. Two contributions could be assigned to lattice oxygen (1: Ni-bound lattice O, "Ni-O", 2: Ir-bound lattice O, "Ir-O", at $\sim 529.5 \mathrm{eV}$ and $\sim 530.0 \mathrm{eV}$ respectively), one contribution was assigned to a surface hydroxyl "OH" species $(\sim 531.3 \mathrm{eV})$ and finally $\mathrm{H}_{2} \mathrm{O}$ /organic $\mathrm{O}$-species $(\sim 533.0 \mathrm{eV})$. Where applicable, contributions of Ni-OH were fitted in the XPS analysis as well (see SI). On catalysts with a significant amount of TiOx present in the spectra, these contributions were fitted and excluded corresponding to a reference TiOx-OER sample (see SI for further information). See Fig. S19 for the distribution of O1s species and Fig. S20 for the individual O1s fits. On all samples the O1s peak was dominated by surface $\mathrm{OH}$ contributions, except for $\mathrm{IrNi} / \mathrm{NiO} \mathrm{HT}$-ap where the major contribution was Ni-bound lattice oxygen fitting well to the $\mathrm{Ni} 2 \mathrm{p}$ peak shape similar to NiO. IrNi-ap, IrNi HT-ap, IrNiOx-ap and IrNiOx HT-ap show small contributions of lattice oxygen bound by $\mathrm{Ni}$ as well.

Upon oxidation and $\mathrm{Ni}$ leaching during OER the Ni-O lattice contribution vanished on all samples except for $\mathrm{IrNi} / \mathrm{NiO} \mathrm{HT}$ $O E R$ where it was still a major component, but now being surpassed by surface $\mathrm{OH}$ (Fig. 4d). A minor contribution of Ir-O appeared on the metallic -OER samples while it slightly decreased on the oxidic -OER samples. Furthermore, conducting OER increased the $\mathrm{OH}$-surface contribution for all catalysts, with $\operatorname{IrNi}-\mathrm{OER}$ and $\operatorname{IrNi} H T-O E R$ exhibiting the smallest change. Interestingly, the surface $\mathrm{OH}$ contribution of $\mathrm{Ir}-\mathrm{OER}$ reached similar levels as the $\operatorname{IrNi}(H T)-O E R$ and IrNiOx (HT)-OER samples (85-90\%), while the remaining monometallic iridium (oxide) catalysts only exhibited about 65 $70 \% \mathrm{OH}$. With below $60 \% \mathrm{IrNi} / \mathrm{NiO} \mathrm{HT}$-OER developed the lowest amount of $\mathrm{OH}$ contribution. The $\mathrm{H}_{2} \mathrm{O}$ /organic species contribution to the O1s spectra was comparably low on all samples and remained essentially unchanged after OER.
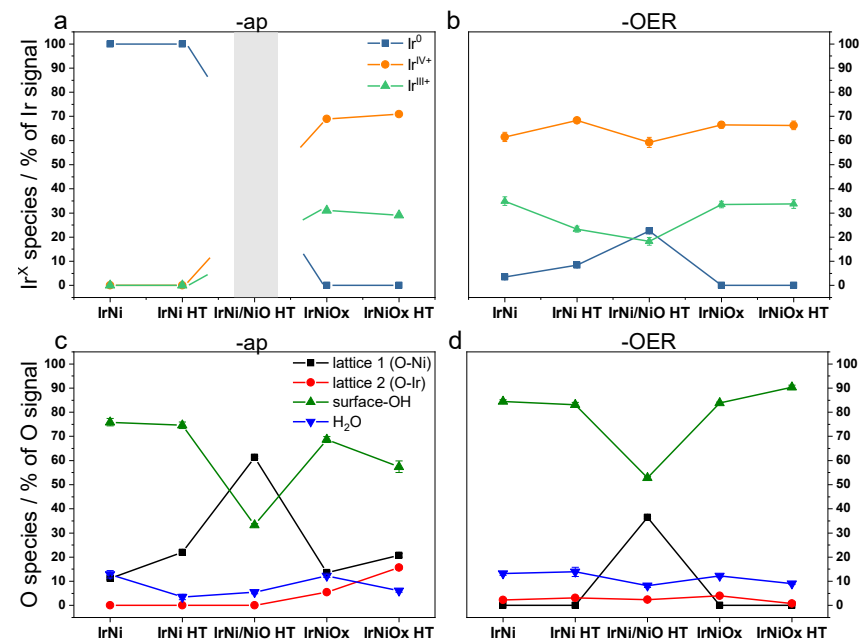

Fig. 4: XPS results for Ir4f contributions in the a) $-a p$ and b) $-O E R$ states as well as $\mathrm{O} 1 \mathrm{~s}$ contributions in the c) - ap and d) $-O E R$ states of the investigated bimetallic catalysts. As no Ir4f signal could be detected on $\mathrm{IrNi} / \mathrm{NiO} \mathrm{HT}$-ap, no statement about the distribution of Ir species can be made.

Physicochemical and morphological changes by heat treatment and OER

As discussed extensively in the past ${ }^{12,14,39}$, heat treatment has a strong influence on the mechanical catalyst stability, which is reflected by the catalyst loss observed on the non-heattreated -OER samples. The second impact of heat treatment is chemical change. As shown by Reier et al. Ti substrates used for the preparation of Ir oxide films start to oxidize at $450{ }^{\circ} \mathrm{C}$ in air. ${ }^{14}$ Despite the detrimental effect on activity, this might help to "anchor" the catalyst layer on the substrate. Indeed, a mixed Ti-Ir-Ni interlayer existed between substrate and catalyst layer of $\mathrm{IrNi} / \mathrm{NiO} \mathrm{HT}-\mathrm{OER}$ (see Fig. S7c) fitting well to the observed stability and the study by Reier et $a l .{ }^{14}$ In addition, heat treatment with increasing temperature produced more crystalline and less hydrated iridium (oxide) that is reported to have lower OER activity. ${ }^{28}$ Consequently, on almost all samples in this study heat treatment led to reduced $\mathrm{OH}$ and $\mathrm{H}_{2} \mathrm{O}$ species in the surface layer (Fig. 4c) as well as decreased catalyst degradation. A suggested oxide formation scheme on IrNi bimetallic catalysts can be found in the supplemental information (Fig. S21).

\section{Elucidation of experimental OER activity predictors}

In the following we derive general, experimental OER activity predictors from the presented data. We want to emphasize the importance of in operando measurements to elucidate the actual active site(s) and OER mechanism. However, this study focuses on finding easily accessible ex situ descriptors, to facilitate reasonable OER catalyst development tools available to every lab. Such descriptors can help in identifying and narrowing the catalyst range suitable for in operando investigation, too. 
The observed effect of heat treatment on the OER activity can in large part be attributed to catalyst corrosion or rather its mitigation. In the steady state, presented in Fig. 1 and Table 3, the monometallic samples followed the same trend of heat-treated catalysts performing worse than non-heat-treated catalysts that was already observed in initial activities. However, the performance of the bimetallic -HT samples improved over the nonheat-treated samples. In case of IrNiOx this might have been an effect of the before mentioned poor catalyst adhesion in the non-heat-treated samples and the resulting catalyst loss. Both, geometric and mass-based activity normalization, are based on initial values (area and loading), since their change cannot easily be monitored in situ. Thus, smaller geometric area (e.g. temporarily by bubble blockage or permanently by catalyst loss) or reduced loading (e.g. by delamination or dissolution) were not taken into account. However, this would only underestimate the activity and while being imperfect it would not falsify the measurements. Q Qnodic as an electrochemical measurement on the other hand, allowed following changes in the number of species that contribute to the OER (see SI for more information). Despite the above mentioned catalyst loss, the specific activity of IrNiOx-OER compares well to IrNiOx HT-OER, suggesting the formation of the same kind of active species regardless of heat treatment (compare Fig. 1). This correlation was found for $\operatorname{IrOx}$ and $\operatorname{IrOx} H T$ as well. Interestingly, the specific activities did not coincide when comparing initial to final OER activities of $\operatorname{IrOx}$ or $\mathrm{IrNiOx}$. Here, corrosion was the most severe but also the change in $\mathrm{j}_{\text {spec }}$ between initial and steady state was the largest, indicating that besides delamination other (deactivation) mechanisms were contributing to the final activity. A detrimental influence of oxidizing the Ti substrate was found thermochemically ${ }^{14}$ and could have occured at high potentials during OER and simultaneous catalyst delamination, too. Possibly, a very mild heat treatment could improve catalyst adhesion, however, this is out of the scope of this paper.

Despite the remarkable stability of its surface layers, $\mathrm{IrNi} / \mathrm{NiO} \mathrm{HT}$ proved to be the least active bimetallic catalyst in

a

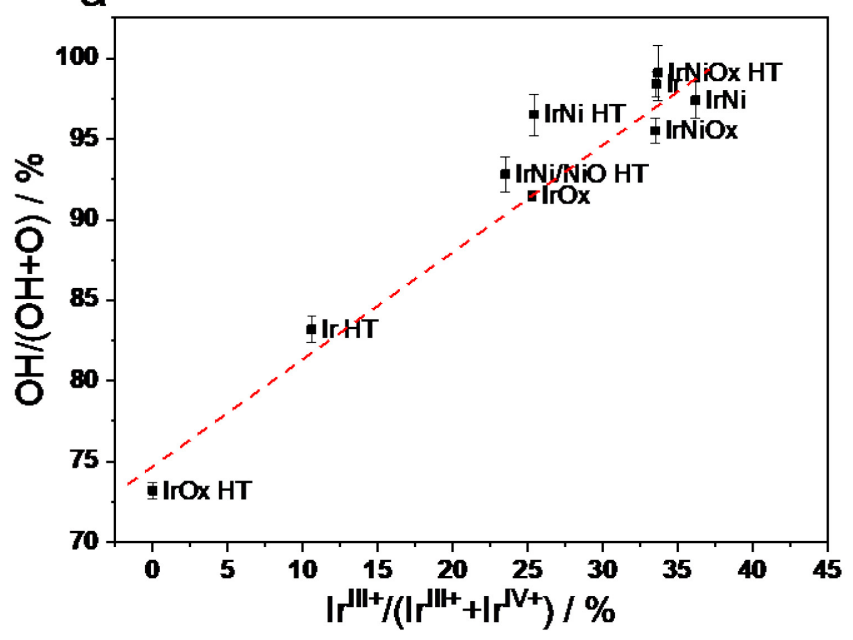

this study. However, it still outperformed the monometallic iridium (oxide) catalysts. While the higher conductivity of the remaining metallic layer underneath the surface oxide of Ir (HT)-OER and IrNi (HT)-OER could be a positive influence on activity of the other metallic samples, this advantage would be inhibited by the semi-conducting $\mathrm{NiO}$ layer on $\mathrm{IrNi} / \mathrm{NiOHT}$ $O E R$ (see Fig. S7 and S21d). Nevertheless, the formation of a stable, Ir-doped $\mathrm{NiO}$ layer could be an interesting catalyst choice for acidic water oxidation.

Independent of it's true origin, the $\mathrm{Ir}^{\mathrm{Z}+}$ species observed at $\sim 62.3 \mathrm{eV}$ in situ by several research groups is discussed as a possible active species of iridium based electrocatalysts for OER. ${ }^{7,}{ }^{40}$ Findings in literature correlate the improved activity of $\mathrm{IrNiOx} T \mathrm{TF}$ catalysts to an increase in and stabilization of surface $\mathrm{OH}$-sites where $\mathrm{Ni}$-vacancies are formed during the electrochemical leaching. ${ }^{20}$ More recent publications assign an electrophilic oxygen $\mathrm{O}^{-\mathrm{I}}$ species as the active site. ${ }^{6,17,40}$ For both interpretations, $\mathrm{Ir}^{\mathrm{III}+}$ detected ex situ could serve as a precursor for the active species that is mostly observed in situ only. Additionally, Massué et al. and Nong et al. recently suggested the combination of both $\mathrm{Ir}^{\mathrm{Z}}$ and electrophilic oxygen, denoted $\mathrm{O}^{(\mathrm{II}-\delta)-}$ into a hole-doped shared active site. ${ }^{22,41}$ Thus, even though the ex situ state differs from the in situ or in operando state it appeared plausible to correlate the $\mathrm{Ir}^{\mathrm{III}+}$-surface concentration $\left(\mathrm{Ir}^{\mathrm{III}+}\right.$ vs. $\mathrm{Ir}^{\mathrm{IV}+}$, calculation see $\left.\mathrm{SI}\right)$ with the observed $\mathrm{OH}-$ surface concentration $(\mathrm{OH}$ vs. lattice $\mathrm{O}$, not to be confused with the surface $\mathrm{OH}$ contribution of the $\mathrm{O} 1 \mathrm{~s}$ peak; calculation see $\mathrm{SI})$. A linear trend of increasing $\mathrm{OH}$-surface concentration with rising $\mathrm{Ir}^{\mathrm{III}}$-surface concentration (see Fig. 5a dashed red line) was found regardless of composition and pretreatment. This correlation is only slightly broken by $\operatorname{IrNi} H T$, which, interestingly, is also the catalyst with the highest observed activity. Hence, ex-situ $\mathrm{Ir}^{\mathrm{III}+}$ content appears to play an important role in the investigated sample set but additional activity promoters may exist on $\operatorname{IrNi} H T$.

b

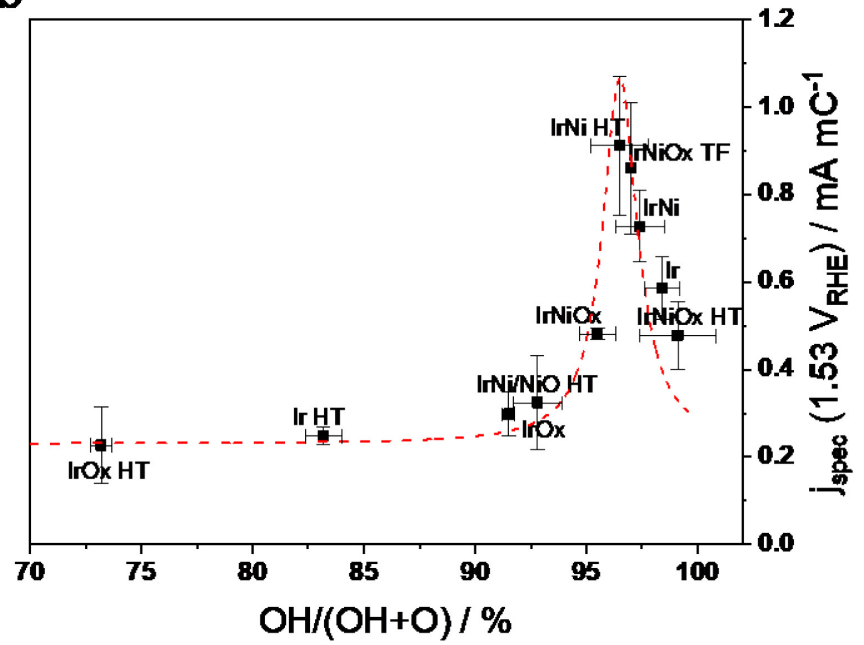

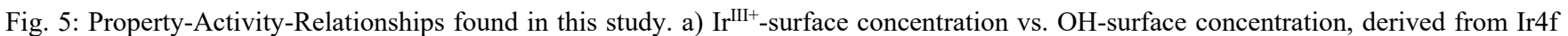
and $\mathrm{O} 1 \mathrm{~s}$ XP spectra. b) Specific activity vs. OH-surface concentration reveals a volcano-type relationship. Specific activity in $0.05 \mathrm{M} \mathrm{H}_{2} \mathrm{SO}_{4}$ was obtained from steady-state SPV measurements at the end of 5 min potentiostatic holds and normalized to Qanodic. IrNiOx TF data taken from Reier et al..$^{20}$ Dashed lines are inserted to guide the reader's eye. 
Furthermore, in Fig. 5b the specific activity was plotted against the $\mathrm{OH}$-surface concentration. Well in line with the observations of Reier et $a l .^{20}$, a high OH-surface concentration correlated with increased OER activity. Based on the present comparison, the former correlation of Reier et al. could be extended to other types of Ir-based OER catalysts leading to a general unprecedented volcano plot presented in Fig. 5b. This volcano plot identified an optimal $\mathrm{OH}$-surface concentration of $\sim 95$ $97 \%$ indicating a small contribution of lattice oxygen to be important as well. This is in excellent agreement with recent findings in literature that propose $\mathrm{OH}$ surface groups on iridium as precursors for the formation of $\mathrm{O}^{(\mathrm{II}-\delta)}$ - active sites. ${ }^{6,17,20,41} \mathrm{Ping}$ et al. calculated surface $\mathrm{OH}$ sites to turn in to the active sites of $\mathrm{IrO}_{2}$ surfaces by deprotonation under OER conditions recently. ${ }^{42}$ Additionally, an in operando XAS study by Pedersen et al. found an $\mathrm{IrO}_{\mathrm{x}}$ surface to be fully covered with adsorbed $\mathrm{O}$ at OER potentials, ${ }^{43}$ both being well in agreement with the suggested relation and experimental data here. Following this observation an activity decrease above 95-97 \% OH-surface concentration is counterintuitive at first. However, if all O-species would be surface $\mathrm{OH}$, there would be no lattice oxygen interconnecting the single IrOx clusters. Without interconnection, the active site density may still increase but, for example, the electron transport throughout the catalyst layer will be considerably inhibited. We believe this to be a possible explanation for the observed volcano maximum. Contrary to the observed volcano relationship at high $\mathrm{OH}$-surface concentrations, no correlation was found for $\mathrm{OH}$-surface concentrations between $70-92 \%$ in Fig. 5b indicating a second governing influence on the specific activity of these catalysts. A high $\mathrm{OH}$-surface concentration could be indicative for increased amorphization, which is supposed to correlate with activity. ${ }^{16}$ Hence, potentially missing flexible structural motifs in the low $\mathrm{OH}$-surface concentration range could be an explanation for the constant, low specific activity of those catalysts.

Since there still has been no agreement on figures of merit for water splitting catalysts, ${ }^{24,}{ }^{44-45}$ we report the mass-based and specific activity at the three most commonly used potentials. Additionally, the Tafel slope and overpotential for a geometric current density of $10 \mathrm{~mA} \mathrm{~cm}$-2 for all catalysts investigated and some reference catalysts are presented in Table 3 as well (see Table S1 for initial activity data and Table S2 for geometric current densities). Especially on those catalysts with heavy catalyst loss (IrOx-OER and IrNiOx-OER) the presented mass activities will underestimate the real activity as the catalyst mass change is not recorded. (Here, the initial activities might give an indication on what could be achieved with a stabilized catalyst layer. However, these values are prone to be affected by other simultaneous processes as discussed above and in the SI.) The steady state specific activities on the other hand, provide insight on the performance regardless of delamination (see discussion above). IrNiOx $T F^{20}, \operatorname{IrNi} N \mathrm{NS}^{19}$ and $\operatorname{IrNi} n w^{18}$ are taken from the corresponding publications. Where possible, missing data points were extracted by Origin's "digitizer" function and are presented in grey due to the higher uncertainty inherent to this method. The Umicore Elyst Ir $75\left(73.9 \mathrm{wt} \% \mathrm{IrO}_{2}\right.$ on $\left.\mathrm{TiO}_{2}\right)$ catalyst was measured in-house under the same conditions as the investigated sample set.

Table 3: Summary of figures of merit at the three most common potentials vs. RHE. Data from the corresponding references has been extracted by Origin's “digitize" function where necessary and should be treated with caution. In case of IrNi NPs

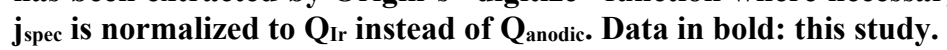

\begin{tabular}{|c|c|c|c|c|c|c|c|c|}
\hline \multirow{2}{*}{ sample } & \multicolumn{3}{|c|}{$\mathbf{j}_{\text {mass }} / \mathbf{A ~ g ~}^{-1} \mathbf{I r}$} & \multicolumn{3}{|c|}{$\mathbf{j}_{\text {spec }} / \mathbf{m A} \mathbf{m} \mathbf{C}^{-1}$} & \multirow{2}{*}{$\begin{array}{l}\text { Tafel slope } \\
\text { / } \mathbf{m V ~} \text { dec }^{-1}\end{array}$} & \multirow{2}{*}{$\begin{array}{l}\eta / \mathrm{mV} \\
\left(10 \mathrm{~mA} \mathrm{~cm}{ }^{-2}\right)\end{array}$} \\
\hline & $1.50 \mathrm{~V}$ & $1.53 \mathrm{~V}$ & $1.55 \mathrm{~V}$ & $1.50 \mathrm{~V}$ & $1.53 \mathrm{~V}$ & $1.55 \mathrm{~V}$ & & \\
\hline Ir & 9 & 39 & 80 & 0.14 & 0.59 & 1.55 & 45 & 293 \\
\hline Ir HT & 2 & 5 & 10 & 0.12 & 0.25 & 0.46 & 48 & 336 \\
\hline IrNi & 123 & 410 & 653 & 0.22 & 0.73 & 1.42 & 35 & 271 \\
\hline IrNi HT & 199 & 632 & 1012 & 0.33 & 0.91 & 1.39 & 37 & 276 \\
\hline $\mathrm{IrNi} / \mathrm{NiO} \mathrm{HT}$ & 13 & 44 & 95 & 0.09 & 0.32 & 0.89 & 64 & 329 \\
\hline IrOx & 4 & 11 & 18 & 0.11 & 0.30 & 0.66 & 71 & 509 \\
\hline IrOx HT & 4 & 21 & 55 & 0.04 & 0.23 & 0.81 & 46 & 349 \\
\hline IrNiOx & 44 & 135 & 263 & 0.15 & 0.48 & 1.20 & 50 & 332 \\
\hline IrNiOx HT & 126 & 540 & 1335 & 0.15 & 0.48 & 1.45 & 33 & 277 \\
\hline $\mathrm{IrNiOx} \mathrm{TF}^{20}$ & 91 & 370 & 759 & 0.21 & 0.86 & 1.77 & 41 & 315 \\
\hline IrNi NPs $^{19}$ & 68 & 311 & 700 & 0.18 & 0.80 & 1.79 & - & 329 \\
\hline Elyst Ir75 & 5 & 14 & 35 & 0.17 & 0.52 & 1.30 & 57 & 460 \\
\hline IrNi nw ${ }^{18}$ & - & 1650 & 3353 & - & - & - & - & - \\
\hline
\end{tabular}

Of the reference catalyst set, $\operatorname{IrOx} H T$-OER is considered to reflect the steady state activity of monometallic Ir (oxide) catalysts the best and was thus taken for comparison. IrNi HT-OER outperformed this reference catalyst by $31 \mathrm{x}$ and $4.6 \mathrm{x}$ in massbased and specific activity, respectively. Even when compared to the industry standard Elyst Ir75 from Umicore (performing outstandingly in RDE and MEA tests ${ }^{46}$ ) the increase is similar (45x and $2 \mathrm{x}$, respectively). IrNiOx HT-OER showed similarly outstanding performance $\left(26 \mathrm{x}\right.$ jmass and $2.1 \mathrm{x} \mathrm{j}_{\text {spec }}$ of IrOx HT$O E R$ ). To the best of our knowledge, these are the highest activities for all thin film iridium-based electrocatalysts for the OER published so far. They are only outperformed by the excellent mass activity of IrNi $n w$ recently published by Alia et $a l .{ }^{18}$ The latter is likely related to the different macrostructure 
of thin films vs. high-surface area nanowires. During the $\mathrm{Ni}$ leaching of thin nanowires the volume-to-surface ratio is affected to a greater extent than on smooth thin films, thus the difference in mass activity. Unfortunately, no specific activity based on $\mathrm{Q}_{\text {anodic }}$ was published and as a result, it is unclear whether the specific activities would compare as it is the case for the three highest performing $\operatorname{IrNi}(\mathrm{Ox})$ catalysts in this study. The roughly similar specific activities of IrNi-OER, IrNiOx (HT)-OER and IrNiOx $T^{20}$ (as IrNi NPs ${ }^{19}$ were normalized to $\mathrm{Q}_{\text {Ir, }}$ comparison was not directly possible) seemed to indicate that for these kind of IrNi-based catalysts the maximum intrinsic activity has been found. However, IrNi HT-OER exhibited increased specific activity, indicating that the structural similarity to $\operatorname{IrNi} N \mathrm{NPS}^{19}$ could act as additional activity promoter. With a more application focused view, improvements are possible by catalyst design and engineering as demonstrated in the $\operatorname{IrNi} n w^{18}$ mass activity.

\section{Conclusions}

This study presents a detailed investigation of the relations between chemical state and OER catalytic activity of a set of sputtered, well-defined iridium-based thin film catalysts in their monometallic and oxide forms as well as bimetallic (oxide) films. The range of their chemical molar Ir:Ni ratios was chosen to straddle that of the most active IrNi-based OER catalysts described in literature. ${ }^{19-20}$ Physico-chemical analysis confirmed that all catalyst films were of comparable uniformity and physicochemical homogeneity, despite the wide range of different types and compositions. Based on the extensive analysis, a model on the surface oxide layer formation of bimetallic IrNi catalysts is suggested.

A few remarkable observations were made in regard to the OER catalytic activity in acidic conditions: To the best of our knowledge, IrNi HT and $\mathrm{IrNiOx} H \mathrm{HT}$ exhibited unprecedented activities among iridium-based thin film catalysts, outperforming the reference catalyst with a $31 \mathrm{x}$ and $4.6 \mathrm{x}$ increase in mass and specific activity, respectively. When compared among all $\operatorname{IrNi}(\mathrm{Ox})$ catalyst types in the literature, IrNi HT exhibited the second-highest mass activity reported. Beyond their nominal OER activity, the present study also suggested interesting catalyst-support interactions for heat-treated catalyst samples based on Ti-Ir-Ni-interlayers, in particular for the $\mathrm{IrNi} / \mathrm{NiO} \mathrm{HT}$-OER catalyst. The presented data further suggests that for mechanistic investigation activity normalization by electrochemical surface area can be beneficial. Unfortunately, no ideal measure of ECSA has been found and agreed upon yet ${ }^{28,44,47}$, making data comparison difficult.

More importantly, the present study firstly uncovered an important close correlation between the ex situ ratio of $\mathrm{Ir}^{\mathrm{III}+}$ concentration in the catalyst surface and the ex situ surface $\mathrm{OH}$ concentration. Either one may serve as a reliable experimental catalytic OER activity predictor for a general volcano relationship, applicable to Ir-based OER electrocatalysts with or without a secondary sacrificial metal ion. The detailed experimental volcano relationship uncovered here suggests as high as possible $\mathrm{Ir}^{\mathrm{III}+}$ surface ratios combined with $\sim 95-97 \%$ surface OH concentration as design targets for active OER catalysts. Both ex situ activity descriptors are in full agreement with insights from extensive in situ/in operando studies. ${ }^{6,16,22,41,43}$ However, unlike operando techniques, the ex situ predictors are much more facile to evaluate, while providing similar indicative power as to the OER catalyst performance. While we acknowledge the importance of in operando measurements, the presented ex situ descriptors can help in developing active materials for large-scale applications and facilitate catalyst design alongside of fundamental research. Due to the surface sensitivity of XPS analysis the presented descriptors can be applied to nanoparticle catalysts without further adaption as long as strong influences of support materials can be ruled out.

\section{AUTHOR INFORMATION}

\section{Corresponding Author}

* Peter Strasser, pstrasser@tu-berlin.de

\section{Author Contributions}

This study was conceived by T.R., D.T., P.B. and C.S. Experiments and analysis were conducted by C.S., P.B., H.N.N., D.T., S.K. and T.R. The manuscript was written and approved in its final version through contributions of all authors.

\section{ASSOCIATED CONTENT}

\section{Supporting Information.}

Detailed experimental description, calculations, Rietveld refinement data, SEM and TEM cross-section micrographs, STEM-EDX line scans, photographs of the catalyst delamination, XPS spectra, additional EDX results, a suggested oxide formation scheme and activity data. This material is available free of charge via the Internet at http://pubs.acs.org.

\section{ACKNOWLEDGMENT}

The authors deeply thank Dr. Arno Bergmann and Benjamin Paul for insightful discussion and advice with Rietveld refinement and SEM-EDX analysis, respectively. Technical support for the (S)TEM measurements by TUB's center for electron microscopy (ZELMI) is gratefully acknowledged. The authors thank Dr. Dirk Berger for preparation of the FIB lamella for the cross-section analysis of $\mathrm{IrNi} / \mathrm{NiO}$ HT-OER.

\section{REFERENCES}

1. Schalenbach, M.; Zeradjanin, A. R.; Kasian, O.; Cherevko, S.; Mayrhofer, K. J. J., A Perspective on Low-Temperature Water Electrolysis - Challenges in Alkaline and Acidic Technology. Int J Electrochem Sc 2018, 13, 1173-1226.

2. Ayers, K., Gigawatt-scale renewable hydrogen via water splitting as a case study for collaboration: The need to connect fundamental and applied research to accelerate solutions. MRS Energy \& Sustainability 2017, 4, E11.

3. Reier, T.; Nong, H. N.; Teschner, D.; Schlögl, R.; Strasser, P., Electrocatalytic Oxygen Evolution Reaction in Acidic Environments - Reaction Mechanisms and Catalysts. Advanced Energy Materials 2016, 1601275 .

4. $\quad$ Carmo, M.; Fritz, D. L.; Merge, J.; Stolten, D., A comprehensive review on PEM water electrolysis. Int J Hydrogen Energ 2013, $38,4901-4934$.

5. $\quad$ Binninger, T.; Mohamed, R.; Waltar, K.; Fabbri, E.; Levecque, P.; Kotz, R.; Schmidt, T. J., Thermodynamic explanation of the universal correlation between oxygen evolution activity and corrosion of oxide catalysts. Sci Rep 2015, 5, 12167.

6. $\quad$ Pfeifer, V.; Jones, T. E.; Velez, J. J. V.; Massue, C.; Greiner, M. T.; Arrigo, R.; Teschner, D.; Girgsdies, F.; Scherzer, M.; Allan, J.; Hashagen, M.; Weinberg, G.; Piccinin, S.; Havecker, M.; KnopGericke, A.; Schlogl, R., The electronic structure of iridium oxide electrodes active in water splitting. Phys Chem Chem Phys 2016, 18, 22922296. 
Casalongue, H. G. S.; Ng, M. L.; Kaya, S.; Friebel, D.; Ogasawara, H.; Nilsson, A., In Situ Observation of Surface Species on Iridium Oxide Nanoparticles during the Oxygen Evolution Reaction. Angew Chem Int Edit 2014, 53, 7169-7172.

8. $\quad$ Halck, N. B.; Petrykin, V.; Krtil, P.; Rossmeisl, J., Beyond the volcano limitations in electrocatalysis - oxygen evolution reaction. Phys Chem Chem Phys 2014, 16, 13682-13688.

9. Oakton, E.; Lebedev, D.; Povia, M.; Abbott, D. F.; Fabbri, E.; Fedorov, A.; Nachtegaal, M.; Copéret, C.; Schmidt, T. J., IrO2TiO2: A High-Surface-Area, Active, and Stable Electrocatalyst for the Oxygen Evolution Reaction. Acs Catal 2017, 7, 2346-2352.

10. Siracusano, S.; Baglio, V.; Grigoriev, S. A.; Merlo, L.; Fateev, V. N.; Aricò, A. S., The influence of iridium chemical oxidation state on the performance and durability of oxygen evolution catalysts in PEM electrolysis. J Power Sources 2017, 366, 105-114.

11. Cherevko, S.; Geiger, S.; Kasian, O.; Mingers, A.; Mayrhofer, K. J. J., Oxygen evolution activity and stability of iridium in acidic media. Part 2. - Electrochemically grown hydrous iridium oxide. $J$ Electroanal Chem 2016, 774, 102-110.

12. Ouattara, L.; Fierro, S.; Frey, O.; Koudelka, M.; Comninellis, C., Electrochemical comparison of IrO2 prepared by anodic oxidation of pure iridium and $\mathrm{IrO} 2$ prepared by thermal decomposition of H2IrC16 precursor solution. $J$ Appl Electrochem 2009, 39, 1361-1367. 13. Li, T.; Kasian, O.; Cherevko, S.; Zhang, S.; Geiger, S.; Scheu, C.; Felfer, P.; Raabe, D.; Gault, B.; Mayrhofer, K. J. J., Atomicscale insights into surface species of electrocatalysts in three dimensions. Nature Catalysis 2018, 1, 300-305.

14. Reier, T.; Teschner, D.; Lunkenbein, T.; Bergmann, A.; Selve, S.; Kraehnert, R.; Schlogl, R.; Strasser, P., Electrocatalytic Oxygen Evolution on Iridium Oxide: Uncovering Catalyst-Substrate Interactions and Active Iridium Oxide Species. J Electrochem Soc 2014, 161, F876-F882.

15. Özer, E.; Spöri, C.; Reier, T.; Strasser, P., Iridium(1 11 1), Iridium(1 110$)$, and Ruthenium(l 0001 ) Single Crystals as Model Catalysts for the Oxygen Evolution Reaction: Insights into the Electrochemical Oxide Formation and Electrocatalytic Activity. Chemcatchem 2017, 9, 597-603.

16. Willinger, E.; Massué, C.; Schlögl, R.; Willinger, M. G., Identifying Key Structural Features of IrOx Water Splitting Catalysts. J Am Chem Soc 2017.

17. Saveleva, V. A.; Wang, L.; Teschner, D.; Jones, T.; Gago, A. S.; Friedrich, K. A.; Zafeiratos, S.; Schlogl, R.; Savinova, E. R., Operando Evidence for a Universal Oxygen Evolution Mechanism on Thermal and Electrochemical Iridium Oxides. J Phys Chem Lett 2018, 9, 3154-3160

18. Alia, S. M.; Shulda, S.; Ngo, C.; Pylypenko, S.; Pivovar, B S., Iridium-Based Nanowires as Highly Active, Oxygen Evolution Reaction Electrocatalysts. Acs Catal 2018, 8, 2111-2120.

19. Nong, H. N.; Oh, H. S.; Reier, T.; Willinger, E.; Willinger, M. G.; Petkov, V.; Teschner, D.; Strasser, P., Oxide-Supported IrNiOx Core-Shell Particles as Efficient, Cost-Effective, and Stable Catalysts for Electrochemical Water Splitting. Angew Chem Int Edit 2015, 54, 2975-2979.

$20 . \quad$ Reier, T.; Pawolek, Z.; Cherevko, S.; Bruns, M.; Jones, T.; Teschner, D.; Selve, S.; Bergmann, A.; Nong, H. N.; Schlögl, R.; Mayrhofer, K. J. J.; Strasser, P., Molecular Insight in Structure and Activity of Highly Efficient, Low-Ir Ir-Ni Oxide Catalysts for Electrochemical Water Splitting (OER). J Am Chem Soc 2015, 137, 1303113040.

21. Nong, H. N.; Gan, L.; Willinger, E.; Teschner, D.; Strasser, P., IrOx core-shell nanocatalysts for cost- and energy-efficient electrochemical water splitting. Chem Sci 2014, 5, 2955-2963.

22. Nong, H. N.; Reier, T.; Oh, H.-S.; Gliech, M.; Paciok, P.; Vu, T. H. T.; Teschner, D.; Heggen, M.; Petkov, V.; Schlögl, R.; Jones, T.; Strasser, P., A unique oxygen ligand environment facilitates water oxidation in hole-doped IrNiOx core-shell electrocatalysts. Nature $\mathrm{Ca}$ talysis 2018, 1, 841-851.

23. Kuo, D.-Y.; Kawasaki, J. K.; Nelson, J. N.; Kloppenburg, J.; Hautier, G.; Shen, K. M.; Schlom, D. G.; Suntivich, J., Influence of Surface Adsorption on the Oxygen Evolution Reaction on IrO2(110). $J$ Am Chem Soc 2017, 139, 3473-3479.
24. Spöri, C.; Kwan, J. T. H.; Bonakdarpour, A.; Wilkinson, D. P.; Strasser, P., The Stability Challenges of Oxygen Evolving Catalysts: Towards a Common Fundamental Understanding and Mitigation of Catalyst Degradation. Angew Chem Int Ed 2017, 56, 5994-6021.

25. Escudero-Escribano, M.; Pedersen, A. F.; Paoli, E. A.; Frydendal, R.; Friebel, D.; Malacrida, P.; Rossmeisl, J.; Stephens, I. E. L.; Chorkendorff, I., Importance of Surface IrOx in Stabilizing RuO2 for Oxygen Evolution. J Phys Chem B 2018, 122, 947-955.

26. Geiger, S.; Kasian, O.; Ledendecker, M.; Pizzutilo, E.; Mingers, A. M.; Fu, W. T.; Diaz-Morales, O.; Li, Z. Z.; Oellers, T.; Fruchter, L.; Ludwig, A.; Mayrhofer, K. J. J.; Koper, M. T. M.; Cherevko, S., The stability number as a metric for electrocatalyst stability benchmarking. Nature Catalysis 2018, 1, 508-515.

27. Rakousky, C.; Keeley, G. P.; Wippermann, K.; Carmo, M.; Stolten, D., The stability challenge on the pathway to high-current-density polymer electrolyte membrane water electrolyzers. Electrochim Acta 2018, 278, 324-331.

28. Reier, T.; Weidinger, I.; Hildebrandt, P.; Kraehnert, R.; Strasser, P., Electrocatalytic Oxygen Evolution Reaction on Iridium Oxide Model Film Catalysts: Influence of Oxide Type and Catalyst Substrate Interactions. ECS Trans. 2013, 58, 39-51.

29. PASAD. http://www.univie.ac.at/pasad/ (accessed access date: 18.05 .18$)$

30. Gammer, C.; Mangler, C.; Rentenberger, C.; Karnthaler, H. P., Quantitative local profile analysis of nanomaterials by electron diffraction. Scripta Materialia 2010, 63, 312-315.

31. Yeh, J. J.; Lindau, I., Atomic subshell photoionization cross sections and asymmetry parameters: $1 \leqslant Z \leqslant 103$. Atomic Data and Nuclear Data Tables 1985, 32, 1-155.

32. Cherevko, S.; Geiger, S.; Kasian, O.; Kulyk, N.; Grote, J.P.; Savan, A.; Shrestha, B. R.; Merzlikin, S.; Breitbach, B.; Ludwig, A.; Mayrhofer, K. J. J., Oxygen and hydrogen evolution reactions on $\mathrm{Ru}, \mathrm{RuO} 2$, Ir, and $\mathrm{IrO} 2$ thin film electrodes in acidic and alkaline electrolytes: A comparative study on activity and stability. Catal Today 2016, 262, 170-180.

33. Dau, H.; Limberg, C.; Reier, T.; Risch, M.; Roggan, S.; Strasser, P., The Mechanism of Water Oxidation: From Electrolysis via Homogeneous to Biological Catalysis. Chemcatchem 2010, 2, 724-761. 34. Pauporte, T.; Andolfatto, F.; Durand, R., Some electrocatalytic properties of anodic iridium oxide nanoparticles in acidic solution. Electrochim Acta 1999, 45, 431-439.

35. Kotz, R.; Neff, H.; Stucki, S., Anodic Iridium Oxide-Films Xps-Studies of Oxidation-State Changes and O-2-Evolution. J Electrochem Soc 1984, 131, 72-77.

36. Trasatti, S.; Petrii, O. A., Real Surface-Area Measurements in Electrochemistry. Pure Appl Chem 1991, 63, 711-734.

37. Wang, C.; Zhao, Y.; Ximei, Z.; Su, D.; Ding, C.; Li, J.; Jin, H., The effect of the phase structure on physicochemical properties of TMO materials: a case of spinel to bunsenite. CrystEngComm 2017, 19, 5809-5814.

38. Ogasawara, H.; Kaya, S.; Nilsson, A., Operando X-Ray Photoelectron Spectroscopy Studies of Aqueous Electrocatalytic Systems. Top Catal 2016, 59, 439-447.

39. Johnson, B.; Girgsdies, F.; Weinberg, G.; Rosenthal, D.; Knop-Gericke, A.; Schlogl, R.; Reier, T.; Strasser, P., Suitability of Simplified (Ir,Ti)O-x Films for Characterization during Electrocatalytic Oxygen Evolution Reaction. J Phys Chem C 2013, 117, 2544325450 .

40. Pfeifer, V.; Jones, T.; Wrabetz, S.; Massue, C.; Velesco-Velez, J.-J.; Arrigo, R.; Scherzer, M.; Piccinin, S.; Haevecker, M.; KnopGericke, A.; Schlogl, R., Reactive oxygen species in iridium-based OER catalysts. Chem Sci 2016.

41. Massué, C.; Pfeifer, V.; van Gastel, M.; Noack, J.; AlgaraSiller, G.; Cap, S.; Schlögl, R., Reactive Electrophilic OI- Species Evidenced in High-Performance Iridium Oxohydroxide Water Oxidation Electrocatalysts. Chemsuschem 2017, 10, 4786-4798.

42. Ping, Y.; Nielsen, R. J.; Goddard, W. A., The Reaction Mechanism with Free Energy Barriers at Constant Potentials for the Oxygen Evolution Reaction at the IrO2 (110) Surface. J Am Chem Soc 2017, 139, 149-155. 
43. Pedersen, A. F.; Escudero-Escribano, M.; Sebok, B.; Bodin, A.; Paoli, E.; Frydendal, R.; Friebel, D.; Stephens, I. E. L.; Rossmeisl, J.; Chorkendorff, I.; Nilsson, A., Operando XAS Study of the Surface Oxidation State on a Monolayer IrOx on RuOx and Ru Oxide Based Nanoparticles for Oxygen Evolution in Acidic Media. The Journal of Physical Chemistry B 2018, 122, 878-887.

44. Alia, S. M.; Hurst, K. E.; Kocha, S. S.; Pivovar, B. S., Mercury Underpotential Deposition to Determine Iridium and Iridium Oxide Electrochemical Surface Areas. J Electrochem Soc 2016, 163, F3051-F3056.
45. Alia, S. M.; Rasimick, B.; Ngo, C.; Neyerlin, K. C.; Kocha, S. S.; Pylypenko, S.; Xu, H.; Pivovar, B. S., Activity and Durability of Iridium Nanoparticles in the Oxygen Evolution Reaction. $J$ Electrochem Soc 2016, 163, F3105-F3112.

46. Bernt, M.; Siebel, A.; Gasteiger, H. A., Analysis of Voltage Losses in PEM Water Electrolyzers with Low Platinum Group Metal Loadings. J Electrochem Soc 2018, 165, F305-F314.

47. Watzele, S.; Bandarenka, A. S., Quick Determination of Electroactive Surface Area of Some Oxide Electrode Materials. Electroanal 2016, 28, 2394-2399. 


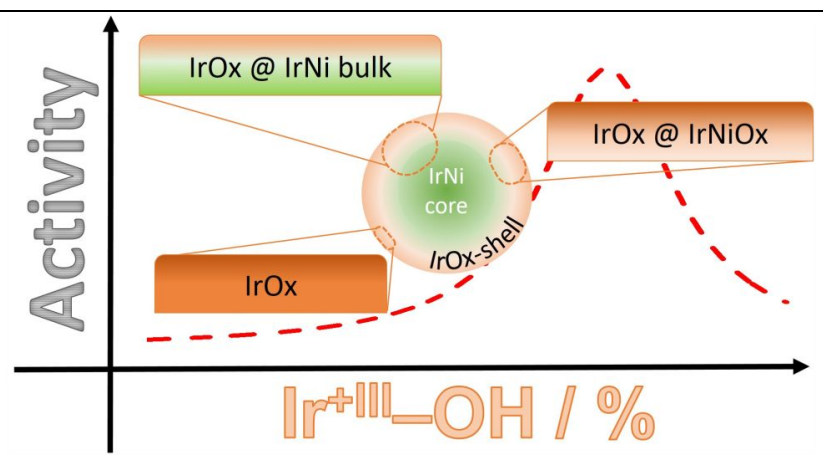

For Table of Contents Only 